\title{
Effects of Rheology and Ice Thickness Distribution in a Dynamic-Thermodynamic Sea Ice Model
}

\author{
T. E. Arbetter, J. A. Curry, and J. A. Maslanik \\ Program in Atmospheric and Oceanic Sciences, Department of Aerospace Engineering Sciences, University of Colorado, \\ Boulder, Colorado
}

(Manuscript received 12 September 1997, in final form 21 December 1998)

\begin{abstract}
Realistic treatment of sea ice processes in general circulation models is needed to simulate properly global climate and climate change scenarios. As new sea ice treatments become available, it is necessary to evaluate them in terms of their accuracy and computational time. Here, several dynamic ice models are compared using both a 2-category and 28-category ice thickness distribution. Simulations are conducted under normal wind forcing, as well as under increased and decreased wind speeds. It is found that the lack of a shear strength parameterization in the cavitating fluid rheology produces significantly different results in both ice thickness and ice velocity than those produced by an elliptical rheology. Furthermore, use of a 28-category ice thickness distribution amplifies differences in the responses of the various models. While the choice of dynamic model is governed by requirements of accuracy and implementation, it appears that, in terms of both parameterization of physical properties and computational time, the elliptical rheology is well-suited for inclusion in a GCM.
\end{abstract}

\section{Introduction}

Arctic sea ice plays an integral role in global climate change. Partial or complete disappearance of the ice cover is hypothesized to bring about profound changes in both regional and global climate. This has been seen in doubled $\mathrm{CO}_{2}$ experiments (e.g., Washington and Meehl 1986; Rind et al. 1995), which indicate that $\mathrm{CO}_{2-}$ induced warming will be enhanced by the thinning and retreat of sea ice in the Arctic. The reason for this increased response is due in part to the sea ice-albedo feedback, in which the disappearance of ice and snow decreases the surface albedo and thereby increases the amount of incident solar radiation absorbed at the surface. This in turn brings about further melt of ice and snow. Also important is the export of sea ice into the Greenland-Iceland-Norwegian (GIN) Sea through Fram Strait. Decadal-scale fluctuations in ice export are hypothesized to be responsible for events such as the Great Salinity Anomaly (e.g., Mysak et al. 1990; Mysak and Power 1992; Hakkinen 1993). A substantial or complete disappearance of the ice could result in an anomalously fresh mixed layer in the GIN Sea, suppressing or even shutting down thermohaline circulation in this region, and affecting climate farther south via the so-

Corresponding author address: Dr. Todd E. Arbetter, Department of Aerospace Engineering Sciences, P.O. Box 429, Boulder, CO 80309-0429.

E-mail: arbetter@cloud.colorado.edu called "conveyor-belt" oceanic circulation (Broecker et al. 1985; Mysak and Power 1992).

The importance of sea ice has been recognized by the climate modeling community (Houghton et al. 1996), and improved parameterizations of its thermodynamic and dynamic processes are being included in general circulation models (GCMs). Inclusion of sea ice in GCMs requires accurate and computationally efficient numerical representations of the main sea ice processes. It is necessary not only to reproduce present-day sea ice conditions correctly, but also to correctly predict how the sea ice will respond to the perturbations associated with climate change.

Sea ice was treated relatively crudely in early GCMs. Ice thermodynamics were included, but ice dynamics were not (e.g., Washington and Meehl 1984). Manabe and Stouffer $(1980,1988)$ used a simple sea ice dynamics model in which the ice drifted freely with the ocean currents if it was less than a certain thickness (4 $\mathrm{m})$. Thicker ice remained stationary. More recently, GCMs have begun to incorporate sophisticated sea ice dynamics parameterizations such as the viscous-plastic rheology (Hibler 1979; e.g., Hibler and Bryan 1987; Fichefet and Morales Maqueda 1997) and the cavitating fluid rheology (Flato and Hibler 1992; e.g., Pollard and Thompson 1994; Weatherly et al. 1997). These rheologies, along with the recently developed elastic-viscous-plastic formulation (Hunke and Dukowicz 1997), are described in section 2 .

Ice dynamics plays an important role in prediction of 
climate change. The choice of ice dynamics parameterization affects modeled ice thickness and transport. Several previous studies can be used to guide our understanding of these effects. Hibler (1979) investigated the importance of parameterization of physical processes using a model with an elliptical (viscous-plastic) ice rheology and a 2-category ice thickness distribution in which ice is separated into categories of thick ice and open water (which included ice of up to $50 \mathrm{~cm}$ thickness). Studies were performed in which the prescribed compressive strength of ice was increased, the shear strength was increased, strength parameterization was altered, and open water was not allowed. Results indicated that the shear strength parameterization was most important in determining the spatial ice thickness variations and ice export. Meanwhile, the open water parameterization was important in determining mean thickness and growth characteristics. However, the effects of the open water parameterization were comparatively small.

Using a multicategory dynamic-thermodynamic sea ice model, Hibler (1980) found that the inclusion of ridging substantially affects the heat exchange characteristics of the Arctic, as thin ice formed by open water production is transferred by ridging to thicker ice categories, creating open water and allowing more thin ice to form thermodynamically. The ice cover was found to be sensitive to both thermodynamic parameterization (in the form of surface albedo) as well as ice strength parameterization (in the form of frictional losses due to ridging). Flato and Hibler (1995), using a model which included separate distributions for level and ridged ice as well as a parameterization for the evolution of snow cover, found that the parameterization of the ridging process-how much thin ice participates in the ridging process and the thickness of the ridges formed-governed both the ice circulation and the amount of energy dissipated by ridging during shear deformation. Factors such as shear strength parameterization also had effects but were not as dominant. Both Hibler (1980) and Flato and Hibler (1995) found the use of an ice thickness distribution produced thicker ice than occurred with the 2-category model.

Using a fully explicit time-stepping numerical scheme, which guarantees energetic consistency, Ip et al. (1991) compared the results of elliptical, square, cavitating fluid, and Mohr-Coulomb rheologies. It was found that the ice drift fields produced by the cavitating fluid and Mohr-Coulomb treatments were faster than those produced by the elliptical and square rheologies, as was the outflow through Fram Strait. This was attributed to the latter two rheologies allowing a greater amount of shear stress. While spatial ice coverage patterns were similar for all four rheologies, the total ice volume was larger for the elliptical and square rheologies, attributed to a larger Fram Strait outflow for the cavitating fluid and Mohr-Coulomb cases.

The effects of compressibility and shear strength were also investigated by Flato and Hibler (1992). Comparing a velocity field produced by an incompressible cavitating fluid model with one produced by free drift, the effects of rheology were apparent, as regions of convergence in the free drift case were removed and the flow was steered along the coast. Allowing some compressibility of the ice resulted in some areas of convergent flow. Comparison of the compressible cavitating fluid results with those of an elliptical (viscous-plastic) rheology and a Mohr-Coulomb rheology, both of which contain some shear strength parameterization, showed that the lack of shear strength in the cavitating fluid parameterization yielded dramatically increased circulation compared to the other two. The Mohr-Coulomb results were intermediate. Spatial ice thickness patterns were similar, although the cavitating fluid case produced thinner ice. This was due in part to increased Fram Strait outflow in the cavitating fluid case, as well as the thinner ice being more readily melted in the summer months. The effects of rheology on ice growth and heat flux were found to be small.

An extensive series of sensitivity tests was performed on a 2-category dynamic-thermodynamic sea ice model by Holland et al. (1993). Among these was a comparison of viscous-plastic rheology with cavitating fluid. While they did not find significant differences in the annual cycles of ice thickness and ice-covered area, the kinetic energy fields associated with the cavitating fluid rheology were $20 \%$ higher, consistent with a generally faster velocity field. They also performed tests on the wind drag parameterization, finding that while a decrease resulted in little change in ice covered area and thickness, an increase in wind drag increased the ice thickness due to enhanced open water production. However, a more complicated treatment of wind drag as a function of ice compactness decreased the ice thickness slightly. More recently, Fichefet and Morales Maqueda (1997) compared the viscous-plastic and cavitating fluid rheologies in a global sea ice-upper ocean model. They found little difference in the seasonal cycles of ice areal coverage, but did notice the cavitating fluid simulation showed a small decrease in ice volume throughout the year, particularly in the Southern Hemisphere. This was due to increased ice transport. The ice velocity fields produced by the cavitating fluid rheology were considerably faster than those of the viscous-plastic rheology. Also, Northern Hemisphere features such as the Beaufort gyre and Transpolar Drift Stream had altered trajectories with the cavitating fluid model, resulting in it having a different spatial distribution of ice thickness, most notably in the Northern Hemisphere. Cavitating fluid ice was generally thicker than viscous-plastic ice in the Canadian basin, while in the Eurasian basin and GIN Sea it was thinner.

The study presented here further defines the effects of ice rheology on simulations of Arctic sea ice cover and considers the role of ice thickness distribution in these simulations. Three numerical formulations of ice rheology and two ice thickness distributions are imple- 
mented. All models are subjected to the same forcing fields. However, the resulting baseline conditions of the various models are not identical. While the models could be tuned to the same baseline conditions, that there are varied responses to the same set of forcings demonstrates the model sensitivity to physical parameterizations. Sensitivity studies are then performed in which each model is subjected to changes in wind speed, and the model responses are intercompared and compared to the baseline runs.

\section{Governing equations and model description}

The dynamics of sea ice is governed by a momentum balance:

$$
m \frac{\partial \mathbf{u}}{\partial t}=-m \hat{f} \mathbf{k} \times \mathbf{u}+\tau_{a}+\tau_{w}-m \hat{g} \boldsymbol{\nabla} H+\mathbf{F}
$$

where, as in Flato and Hibler (1992, 1995), the nonlinear momentum advection term is neglected. Here, $m$ is the ice mass per unit area, $\mathbf{u}$ is the ice velocity, $\hat{f}$ is the Coriolis parameter, $\mathbf{k}$ is a unit vector normal to the surface, $H$ is the sea surface dynamic height, $\hat{g}$ the acceleration due to gravity, and $\mathbf{F}$ is the force due to variation in internal ice stress; $\tau_{a}$ and $\tau_{w}$ are forces due to the air and water stresses given by

$$
\begin{aligned}
\tau_{a}=\rho_{a} C_{a}\left|\mathbf{U}_{g}\right|\left(\mathbf{U}_{g} \cos \phi\right. & \left.+\mathbf{k} \times \mathbf{U}_{g} \sin \phi\right) \\
\tau_{w}=\rho_{w} C_{w}\left|\mathbf{U}_{w}-\mathbf{u}\right| & {\left[\left(\mathbf{U}_{w}-\mathbf{u}\right) \cos \theta\right.} \\
+ & \left.\mathbf{k} \times\left(\mathbf{U}_{w}-\mathbf{u}\right) \sin \theta\right] .
\end{aligned}
$$

Here, $\mathbf{U}_{g}$ is the geostrophic wind, $\mathbf{U}_{w}$ is the ocean current, $C_{a}$ and $C_{w}$ the air and water drag coefficients, $\rho_{a}$ and $\rho_{w}$ the air and water densities, and $\phi$ and $\theta$ turning angles at the ice-air and ice-ocean interfaces. The rheologies considered in this paper differ in their solution for $\mathbf{F}$. These methods are summarized in the next three subsections; the reader is encouraged to refer to the original papers for a more detailed description. Section $2 \mathrm{~d}$ briefly describes the 2-category formulation of the models, while section $2 \mathrm{e}$ describes the ice thickness distribution (28 category) formulation. The thermodynamics used for all models in this study are described in Hibler (1980, appendix B).

\section{a. Viscous-plastic model}

Hibler (1979) presented a rheology in which sea ice is modeled as a nonlinear viscous compressible fluid. Under normal deformation rates the ice acts in a rigidplastic manner, while under very small deformation rates it acts as a linear viscous fluid. The forces due to internal stress are given by

$$
\mathbf{F}=\boldsymbol{\nabla} \cdot \sigma
$$

where $\sigma$ is the two-dimensional stress tensor given by

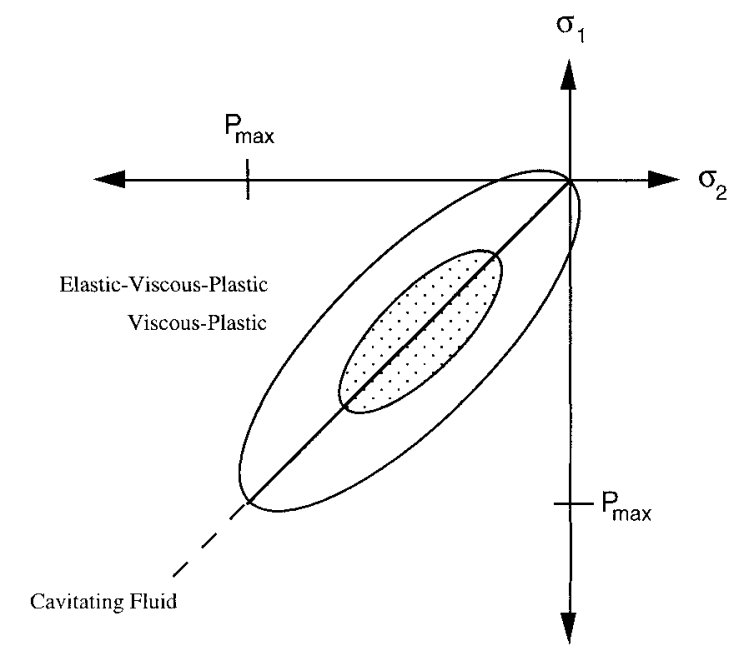

FIG. 1. Yield curves for the elliptical (viscous-plastic, elasticviscous-plastic) and linear (cavitating fluid) rheologies in principal stress space. For very small strain rates, the viscous-plastic stress state moves inside the yield curve to the smaller (shaded) ellipse, approximating a linear viscous fluid. After Hibler (1979), Flato and Hibler (1992).

$$
\sigma_{i j}=2 \eta \dot{\varepsilon}_{i j}+(\zeta-\eta) \dot{\varepsilon}_{k k} \delta_{i j}-\frac{p \delta_{i j}}{2} .
$$

Here, $\dot{\varepsilon}$ is the strain rate, $p$ is the hydrostatic ice pressure (defined below), and $\zeta$ and $\eta$ are nonlinear bulk and shear viscosities, determined by

$$
\begin{gathered}
\zeta=\frac{p}{2 \Delta} \\
\eta=\frac{\zeta}{e^{2}}
\end{gathered}
$$

where

$\Delta=\sqrt{\left(\dot{\varepsilon}_{11}^{2}+\dot{\varepsilon}_{22}^{2}\right)\left(1+e^{-2}\right)+4 e^{-2} \dot{\varepsilon}_{12}^{2}+2 \dot{\varepsilon}_{11} \dot{\varepsilon}_{22}\left(1-e^{-2}\right)}$.

These viscosities are defined such that the stress state lies on an elliptical yield curve (where $e$ is the ratio of major to minor axes of the ellipse) for plastic flow (see Fig. 1). For viscous flow, which occurs at very small strain rates, maximum limits are imposed on $\zeta$ and $\eta$ such that the stress state lies on a smaller, concentric ellipse.

\section{b. Cavitating fluid model}

The cavitating fluid rheology introduced by Flato and Hibler (1992) provides a computationally simpler rheology than viscous-plastic, in which the pack ice does not resist divergence or shear but does resist convergence. The solution for $\mathbf{F}$ becomes simply

$$
F=-\nabla p_{\text {stress }},
$$

where $p_{\text {stress }}$ is the internal ice pressure, equal to the 
magnitude of the principal stresses. [Note the change in notation from Flato and Hibler (1992); $p_{\max }$ (their notation) refers to $p$ here.] Graphically, this yield curve can be seen in Fig. 1. Computationally, the solution is achieved by starting with free drift, then correcting the velocity fields in a manner reflecting the compressive strength of the pack ice:

$$
\begin{array}{ll}
\boldsymbol{\nabla} \cdot(\mathbf{u}+\tilde{\mathbf{u}}) \geq 0 & \text { if } p_{\text {stress }}+\tilde{p}_{\text {stress }}=0 \\
\boldsymbol{\nabla} \cdot(\mathbf{u}+\tilde{\mathbf{u}})=0 & \text { if } 0<p_{\text {stress }}+\tilde{p}_{\text {stress }}<p \\
\boldsymbol{\nabla} \cdot(\mathbf{u}+\tilde{\mathbf{u}}) \leq 0 & \text { if } p_{\text {stress }}+\tilde{p}_{\text {stress }}=p,
\end{array}
$$

where the tilde indicates the corrected field. The first term represents divergence, the third term represents convergence, while the second term represents the incompressibility of the pack ice if it is subject to compressive pressure less than its compressive strength $p$. The iterative solution method for the cavitating fluid rheology is detailed in Flato and Hibler (1992).

\section{c. Elastic-viscous-plastic model}

The elastic-viscous-plastic model presented by Hunke and Dukowicz (1997) incorporates a numerical solution of an elliptical rheology in which an elastic contribution is added to the viscous-plastic equation. This elastic component is introduced for numerical efficiency and is not intended to be physically realistic. Rewriting (5), we obtain

$$
\frac{1}{2 \eta} \sigma_{i j}+\frac{\eta-\zeta}{4 \eta \zeta} \sigma_{k k} \delta_{i j}+\frac{p}{4 \zeta} \delta_{i j}=\dot{\varepsilon}_{i j},
$$

which represents the viscous-plastic contribution to the strain rate. Recognizing that an ice model need only simulate viscous-plastic behavior at timescales on the order of the wind forcing (days), an elastic component is added. This component, rather than a linear viscous approximation (as in Hibler 1979), regularizes the small strain rate case. Hunke and Dukowicz (1997) argue that this component also provides more accuracy under transient behavior while reducing to the original viscousplastic behavior for longer timescales. The elastic contribution is represented by

$$
\frac{1}{E} \frac{\partial \sigma_{i j}}{\partial t}=\dot{\varepsilon}_{i j}
$$

where $E$ is a term analogous to Young's modulus, defined to be a function of compactness and thickness. Summing (11) and (12) yields

$$
\frac{1}{E} \frac{\partial \sigma_{i j}}{\partial t}+\frac{1}{2 \eta} \sigma_{i j}+\frac{\eta-\zeta}{4 \eta \zeta} \sigma_{k k} \delta_{i j}+\frac{p}{4 \zeta} \delta_{i j}=\dot{\varepsilon}_{i j} .
$$

The momentum equation is integrated over an effective elastic-viscous-plastic time step (subcycle) of length $\Delta t_{e}=\Delta t / N$, where $\Delta t$ is the model time step and $N$ is an integer greater than 1 , with the stress tensor $\sigma$ updated every subcycle while the viscosities, compressive strength, and Young's modulus are held constant over a model time step. In the steady-state limit of (13), the elastic contribution disappears and the viscous-plastic solution [(5), (11)] is recovered. As in the viscous-plastic formulation, (6)-(8) are used to determine the bulk and shear viscosities. Further details on the solution method can be found in Hunke and Dukowicz (1997).

\section{d. Two-category formulation}

A 2-category (thick ice and open water) thickness distribution is used by Hibler (1979) using continuity equations for thickness,

$$
\frac{\partial h}{\partial t}=-\frac{\partial(u h)}{\partial x}-\frac{\partial(v h)}{\partial y}+S_{h},
$$

and for area,

$$
\frac{\partial A}{\partial t}=-\frac{\partial(u A)}{\partial x}-\frac{\partial(v A)}{\partial y}+S_{A}
$$

in which $h$ is the mean thickness of the ice and $A$ is the fraction of ice-covered area, defined to be between zero and unity; $u$ and $v$ are directional components of the ice velocity vector $\mathbf{u}$, and $S_{h}$ and $S_{a}$ are thermodynamic source terms defined in Hibler (1979). The internal ice strength is given by

$$
p=p^{*} h \exp [-C(1-A)],
$$

where $p^{*}$ and $C$ are empirical constants given in Flato and Hibler (1992).

\section{e. Twenty-eight-category ice thickness distribution}

Following Thorndike et al. (1975) and Hibler (1980), Flato and Hibler (1995) introduce continuity equations for level and ridged ice:

$$
\begin{aligned}
& \frac{\partial g_{l}}{\partial t}=-\boldsymbol{\nabla} \cdot\left(\mathbf{u} g_{l}\right)-\frac{\partial}{\partial h}\left(f_{l} g_{l}\right)+\Psi_{l}+F_{l} \\
& \frac{\partial g_{r}}{\partial t}=-\boldsymbol{\nabla} \cdot\left(\mathbf{u} g_{r}\right)-\frac{\partial}{\partial h}\left(f_{r} g_{r}\right)+\Psi_{r}+F_{r},
\end{aligned}
$$

where $g_{l}$ and $g_{r}$ are the level and ridged ice thickness distributions, and $f_{l}$ and $f_{r}$ are the level and ridged ice thermodynamic growth rates, defined to be identical $\left(f_{r}\right.$ $\left.=f_{l}=f\right) ; \psi_{l}$ and $\psi_{r}$, the level and ridged ice redistribution functions, and $F_{l}$ and $F_{r}$, the thermodynamic source terms, are defined in Flato and Hibler (1995). A detailed description of the theory and numerical solution of a two-dimensional dynamic-thermodynamic ice thickness distribution model can by obtained by consulting Hibler (1980) and Flato and Hibler (1995).

The constraint proposed by Rothrock (1975), namely that the potential energy of the displaced water per unit area is equal to the sum of the energy of the ice and the energy required to displace the water, implies 


$$
p=C_{f} C_{p} \int_{0}^{\infty}\left(\omega_{l}+\omega_{r}\right) h^{2} d h,
$$

where $C_{p}$ is a constant depending on the densities of ice and water and $C_{f}$ is the ratio of total energy losses to potential energy change, defined by Flato and Hibler (1995) to be 17; $\omega_{l}$ and $\omega_{r}$ are ridging modes detailed in Flato and Hibler (1995). A method for numerically evaluating (19) is given in Hibler (1980, appendix C) and is implemented here.

The total normalized energy dissipation rate can be obtained from (5):

$$
p^{-1} \sigma_{i j} \dot{\varepsilon}_{i j}=\frac{1}{2}\left(\Delta-\dot{\varepsilon}_{k k}\right) .
$$

Similarly, it can be derived from (13) if the elastic contribution is neglected. The right side of (20) can be separated into components representing energy dissipated by shear and by convergence, respectively:

$$
p^{-1} \sigma_{i j} \dot{\varepsilon}_{i j}=\frac{1}{2}\left(\Delta-\left|\dot{\varepsilon}_{k k}\right|\right)-\min \left(\dot{\varepsilon}_{k k}, 0\right) .
$$

The energy dissipated by ridging is taken to be

$$
M=C_{s} \frac{1}{2}\left(\Delta-\left|\dot{\varepsilon}_{k k}\right|\right)-\min \left(\dot{\varepsilon}_{k k}, 0\right),
$$

where $M$ is the normalized mechanical energy dissipation rate due to ridge creation; $C_{S}$ is the fraction of the shearing component of mechanical energy dissipated by ridging, and is set to 0.5 for the viscous-plastic and elastic-viscous-plastic formulations. For the cavitating fluid rheology, the ratio of major to minor axes $e$ of the "elliptical" yield curve goes to infinity, and thus (8) reduces to

$$
\Delta=\left|\dot{\varepsilon}_{k k}\right|
$$

(i.e, the positive root of the square of the sum of the principal strains), and the first term on the right-hand side of (21) and (22) is identically zero. Thus, analogous to the large-scale rheology, no energy is dissipated by shear ridging in the cavitating fluid rheology; (21) and (22) are identical, and all energy dissipated is due to convergence (G. Flato 1997, personal communication).

\section{Model implementation and the baseline runs}

The models used here are identical with the exception of ice rheology and ice thickness distribution. The thermodynamics are essentially the same as those described in Hibler (1980, appendix B). The model domain is an 80-km rectangular Cartesian grid, resolving the Arctic Ocean and adjacent seas including the GIN Sea south to Iceland as well as portions of the Bering Sea. The annual and monthly averages presented here consider the Arctic basin as defined in Gloersen et al. (1992). Forcing fields are derived from National Centers of Environmental Prediction reanalysis fields for 1992 at 6- $\mathrm{h}$ intervals for surface air temperature, specific humidity, downwelling shortwave and longwave radiation, and geostrophic winds computed from sea level pressure. A latitudinally varying Coriolis parameter is used. The models are integrated for 30 years using 6-h time steps. The numerical solver described in Zhang and Hibler (1997) is used for the viscous-plastic rheology, with 1, 5 , and 15 iterations implemented in the solver to compare approximations to a plastic response. Modifications are also made to the cavitating fluid rheology to accommodate the high frequency $(6 h)$ of the forcing by using a tighter convergence condition. This is necessary in order to maintain numerical stability for the cavitating fluid solver (G. Flato 1997, personal communication). The elastic-viscous-plastic numerical model is implemented using its standard implementation of $N=100$ subcycles. While it is possible to increase or decrease the effect of the elastic waves by decreasing or increasing the value of $N$, this is not investigated here. The ice thickness bins for the 28-category ice thickness distribution are given in Flato and Hibler (1995). Since there was little natural variability in the runs once equilibrium was reached, baseline averages are obtained in all cases by considering year 30 of the normal wind scenario.

Recently, the Sea Ice Model Intercomparison Project (SIMIP) (Lemke et al. 1997; see also http:// www.ifm.uni-kiel.de/me/research/Projekte/SIMIP/simip.html) has compiled requirements for a numerical model to be considered a valid implementation of a plastic rheology. Namely, the scheme should asymptotically approach the exact solution for the stress state with a sufficient number of iterations on the numerical solver. As noted in Zhang and Hibler (1997), the linearization of the bulk and shear viscosities in their solution procedure yields only an approximation to plastic flow. Thus, it is necessary to repeat the solution procedure a number of times for each time step. Zhang and Hibler (1997) recommend 15 iterations as close to true plastic flow; thus, we choose viscous-plastic with 15 iterations as our reference solution for this study. Figure 2 shows the normalized stress states $(\sigma / p)$ for a typical day in winter once equilibrium has been reached. It is seen that, for both 2- and 28-category formulations, nearly all of the stress states lie on or within the elliptical yield curve.

\section{a. Two-category simulations}

The annual averages of thickness, areal coverage, and total kinetic energy per unit mass, as well as the March and September monthly means from the baseline twolayer simulations are given in Table 1. It is seen that the values for the viscous-plastic rheologies increase asymptotically with increased number of iterations used in the numerical solver. Values of total kinetic energy per unit mass, indicative of the overall motion of the ice, decrease asymptotically with the number of iterations on the plastic solver for the annual averages. For 
a)

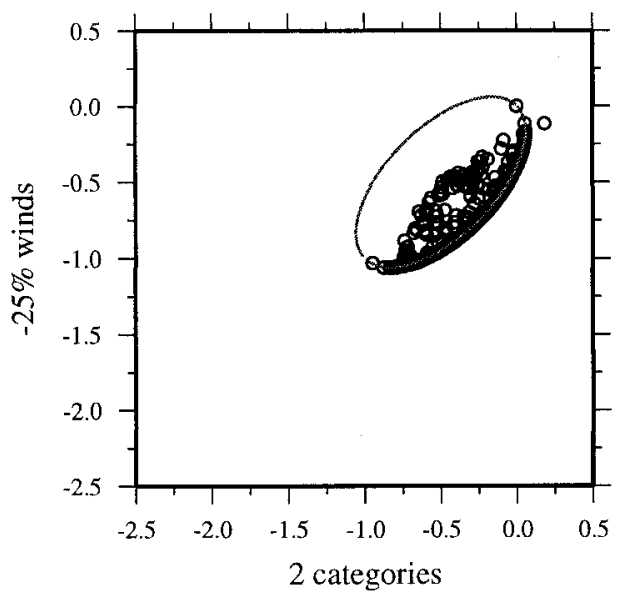

b)

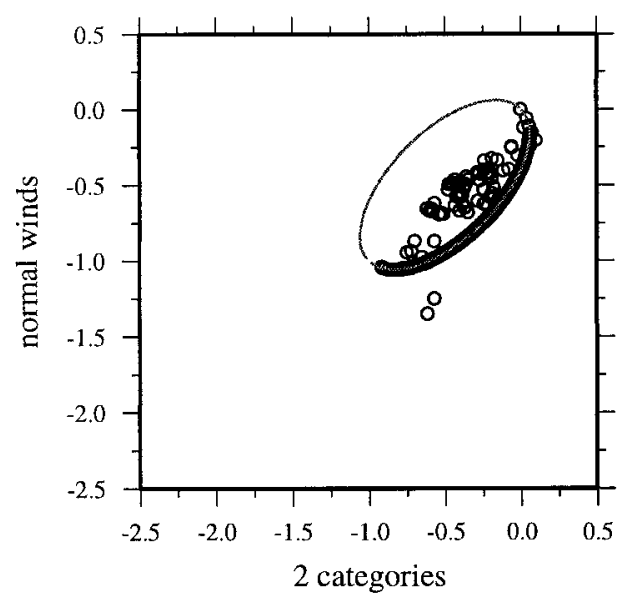

c)

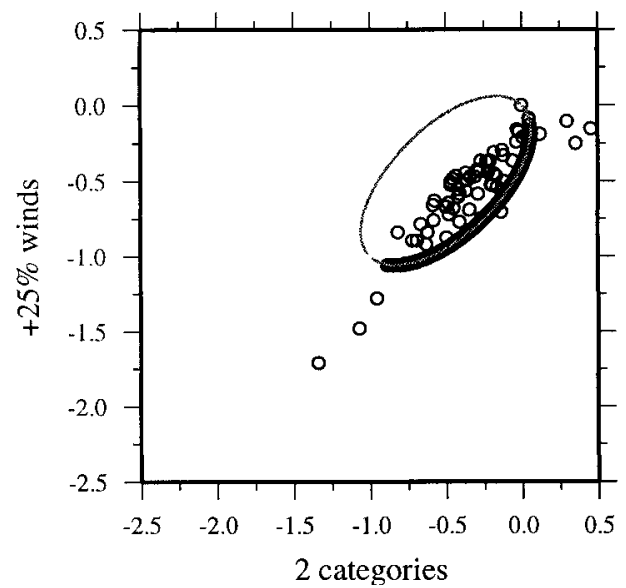

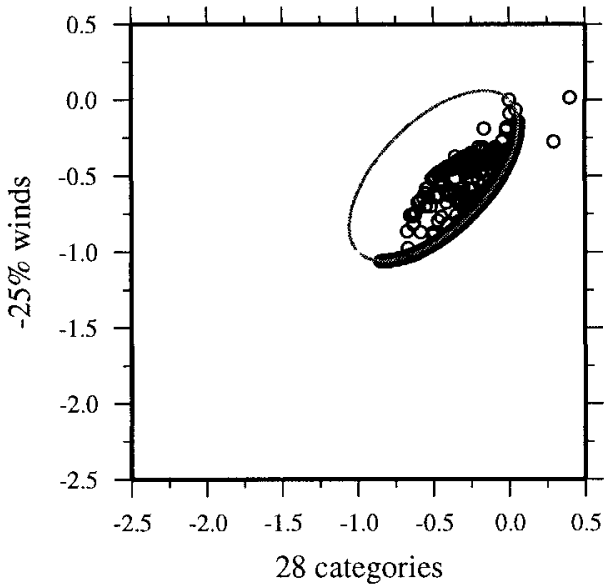
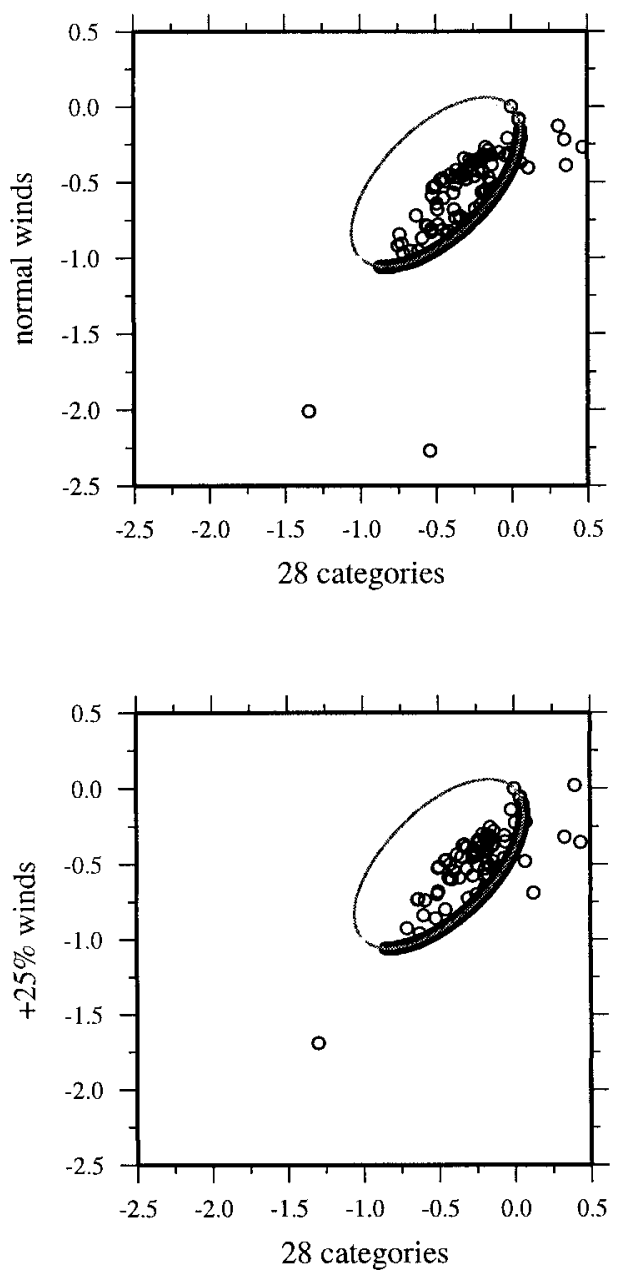

FIG. 2. Normalized stress states for a typical winter day for the viscous-plastic model with 15 iterations on the numerical solver: (a) $-25 \%$ wind speed case, 2 categories (left) and 28 categories (right); (b) normal wind speed case, 2 categories (left) and 28 categories (right); (c) $+25 \%$ wind speed case, 2 categories (left) and 28 categories (right). 
the March values (high areal coverage), the speed of the flow increases slightly, while for September (low areal coverage) there is no pattern. However, these results suggest that a better approximation of a plastic solution may be important.

The elastic-viscous-plastic model gives ice thickness slightly thinner (about $5 \mathrm{~cm}$ ) than the viscous-plastic formulation, while areal ice coverage is about the same. The total kinetic energy values are about $10 \%$ higher for the annual and March averages, although the September values are actually lower than those of the viscous-plastic results. This results from the slightly different treatment of the small strain rate regime. Stress state plots (not shown, see e.g., Hunke and Zhang 1999) indicate that the solution method is not obeying the elliptical yield curve rule. The cavitating fluid rheology average thicknesses are notably thinner than any of the elliptical yield curve results (viscous-plastic, elasticviscous-plastic), while there is slightly more ice-covered area. We note also that the spatial thickness pattern of the cavitating fluid rheology differs from that of the elliptical formulations (not shown, see e.g., Flato and Hibler 1992). Furthermore, kinetic energy values for cavitating fluid are higher than any of the elliptical yield curve cases. This is primarily due to the lack of shear strength in the cavitating fluid rheology.

\section{b. Ice thickness distribution simulations}

The average thicknesses and areal coverages and total kinetic energy per unit mass for the 28-category simulations are given in Table 2. While the tendencies seen in the 2-category simulations are repeated here, the addition of a multiple layer ice thickness distribution not only substantially increases the average ice thicknesses, but also enhances the differences between the different rheologies. This is most obvious in comparing the cavitating fluid rheology with the elliptical yield curve results. The increased difference between the elastic-viscous-plastic and viscous-plastic formulations is not insignificant, however. Average areal coverages are also increased, most significantly in September. Kinetic energy per unit mass values decrease for all cases, most notably in March, due to the substantial increase in ice thickness (mass).

The thickness differences are examined spatially in Fig. 3. Here, the spatial thickness pattern of the viscousplastic 15-iteration run for March is shown. The other solutions are subtracted from the reference, and their thickness anomalies are shown. The most obvious differences are again with the cavitating fluid model, where it is readily seen that the ice is thinner over most of the model domain. The viscous-plastic solution with one iteration has thicker ice along the Canadian coast, while a slightly thinner area in the region north of Fram Strait. The viscous-plastic 5-iteration solution is nearly identical to the 15-iteration reference solution. The elasticviscous-plastic solution has thinner ice over most of the 


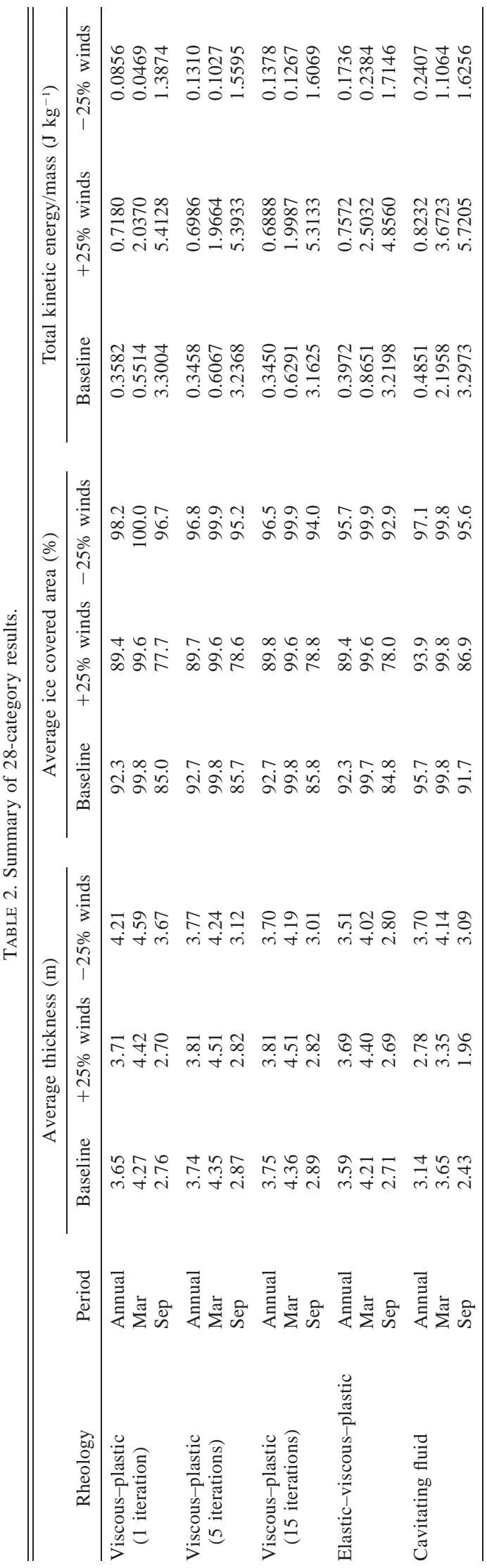

Arctic Basin, particularly in the Beaufort Sea and in the area surrounding Svalbard, including Fram Strait.

Figure 4 shows the mean ice drift for the month of March. While all formulations show the same general pattern, the cavitating fluid model shows faster drift, particularly in the Beaufort Sea. This increased ice speed is typical of cavitating fluid and has been observed before (e.g., Ip et al. 1991; Flato and Hibler 1992; Holland et al. 1993; Fichefet and Morales Maqueda 1997). Also of note is a region of eastward transport north of the coast of Greenland that is much slower in the other rheologies. This is due to the lack of shear strength in the cavitating fluid rheology. Ice flow is unimpeded, even in areas of thick ice where shear strength would otherwise inhibit the flow. As will be seen later, the outflow of ice through Fram Strait is also affected by the rheology. The viscous-plastic models show increasing ice drift with increased iterations on the numerical solver, while the elastic-viscous-plastic solution resembles the viscous-plastic cases, with slightly faster drift in the Beaufort Sea.

As the 28-category ice thickness distribution explicitly includes ridged ice, the fraction of ridged ice-covered area can be determined, as seen in Fig. 5. Again, the most obvious differences are between cavitating fluid and the elliptical models. The cavitating fluid results show substantially less ridged ice, with most of it concentrated along the Canadian archipelago and the north coast of Alaska. As explained in section 2e, the only energy dissipated by the ridging process is due to convergence. The ridging parameterization is driven by net convergence into a grid cell (Hibler 1980), and thicker ice is more incompressible, resisting this convergence. Thus, with no shear contribution to ridging, there is less ridged ice than in the elliptical yield curve results in which shear deformation contributes to the production of ridged ice. The elliptical yield curve results vary slightly but are in general agreement as to the location and amount of ridged ice.

\section{c. Computational time requirements}

It is worthwhile to consider the central processing unit (CPU) time required for each model, as this is a consideration for inclusion in GCMs. Table 3 summarizes the total CPU time required for a 20-yr simulation. It is seen that the addition of a 28-category ice thickness distribution substantially increases the CPU time required for all rheologies. While Zhang and Hibler (1997) recommend 10 to 15 iterations to more fully approximate a plastic solution, a substantial amount of CPU time is required for increased iterations. The use of a viscous-plastic rheology with only one iteration on the numerical solver was fastest, but both Zhang and Hibler (1997) and Hunke and Dukowicz (1997) indicate that one iteration is not sufficient to approximate a plastic solution. The cavitating fluid rheology requires nearly twice as much CPU time as the elastic-viscous-plastic 
(a)

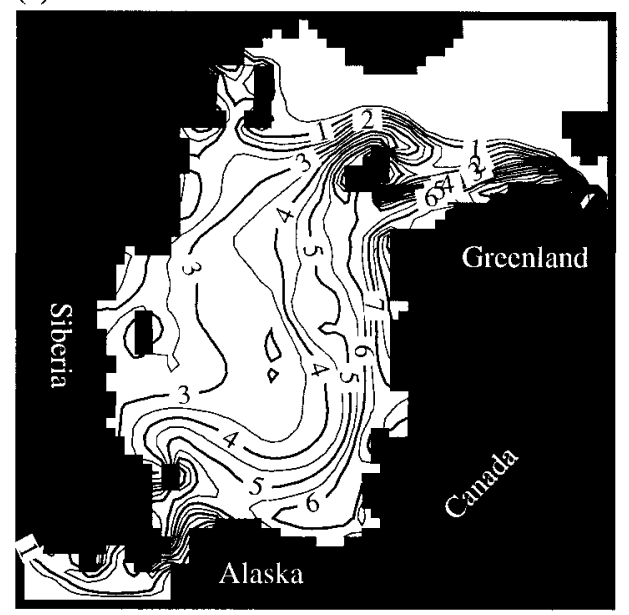

(b)

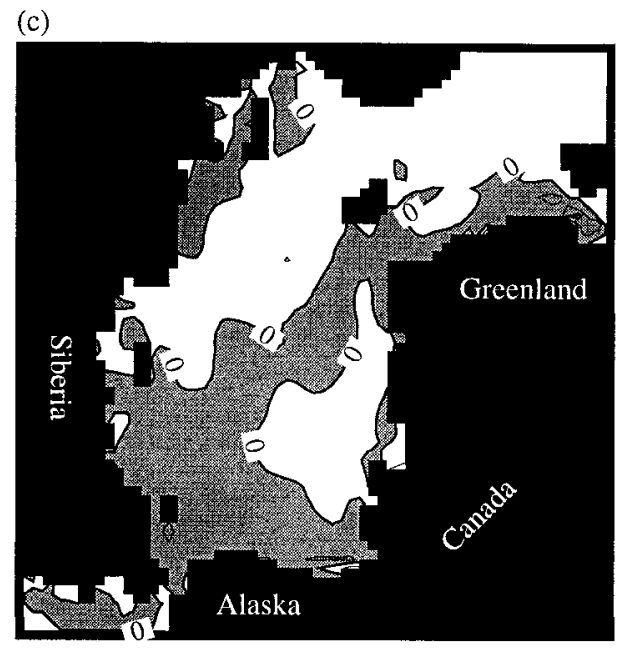

(d)
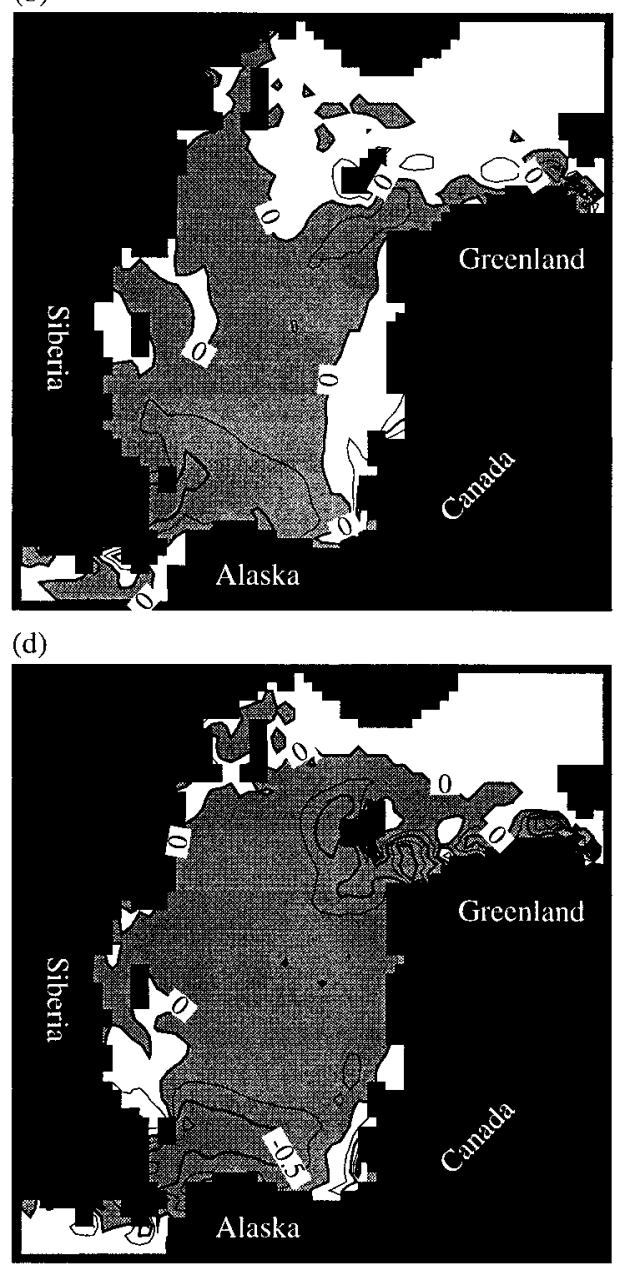

(e)

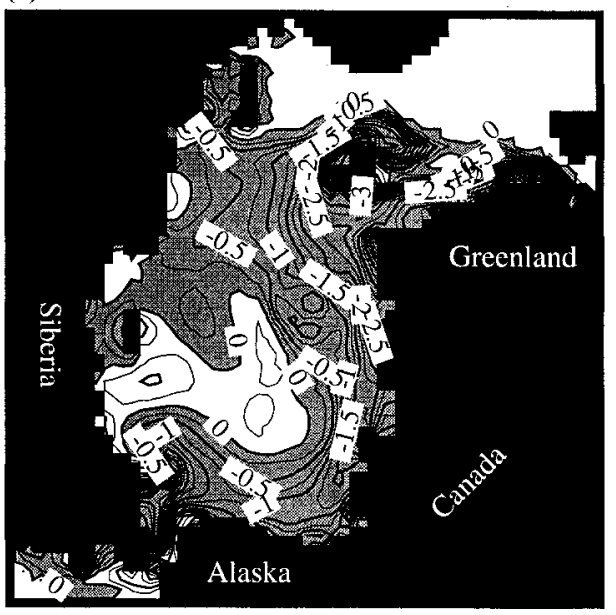

FIG. 3. (a) Baseline March ice thickness results (m) for viscous-plastic, 15 iterations. (b-e) Thickness anomaly (m) from viscous-plastic, 15 iterations, for (b) viscous-plastic, 1 iteration, (c) viscous-plastic, 5 iterations, (d) elasticviscous-plastic, (e) cavitating fluid. Negative anomalies are gray shaded. 

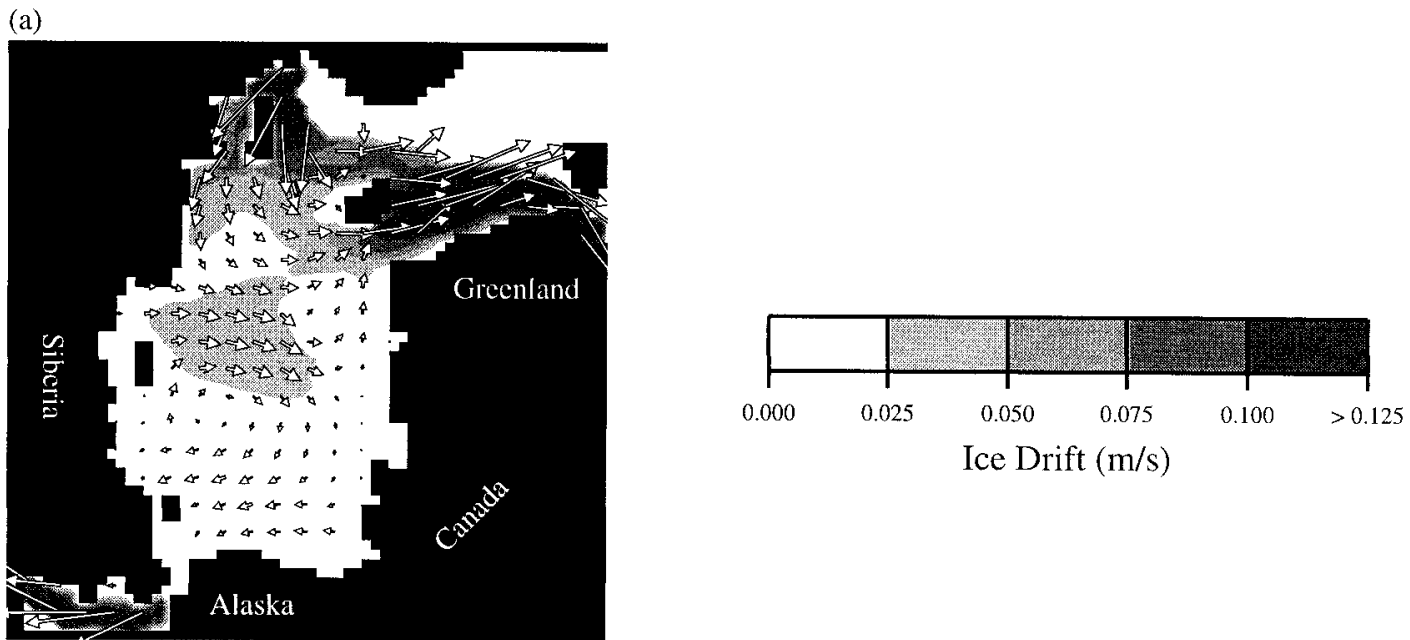

(b)

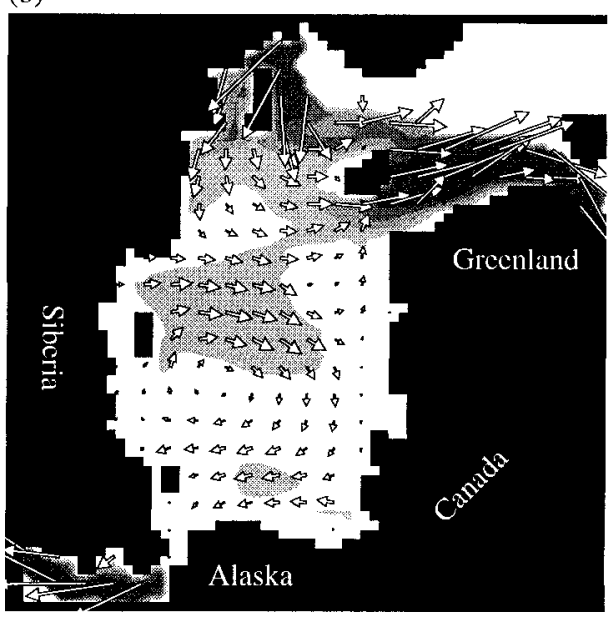

(c)

(d)
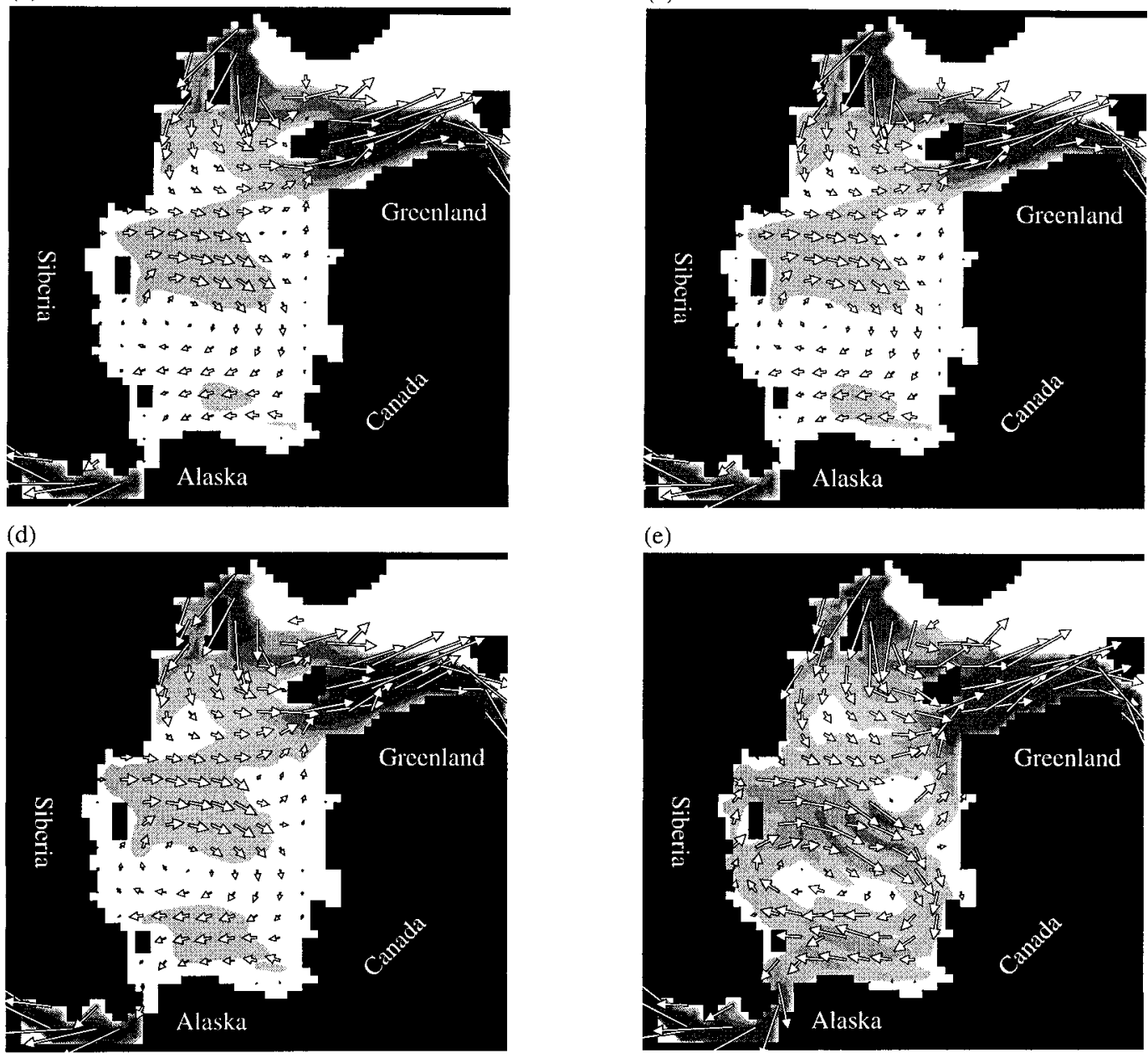

(e)

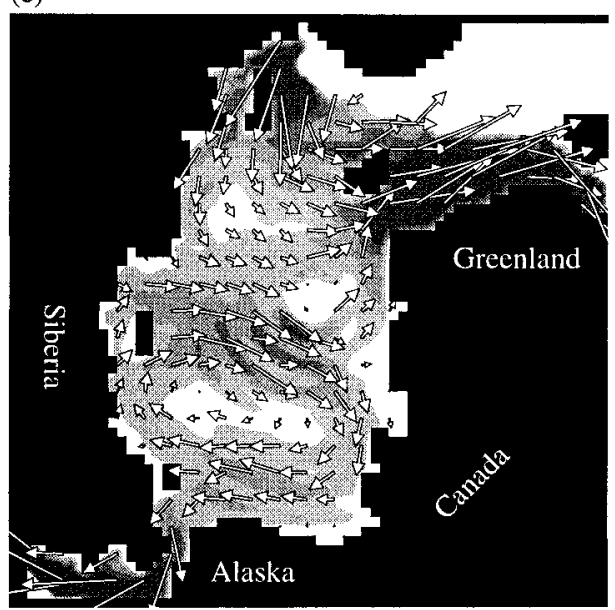

Fig. 4. Baseline March ice drift results for (a) viscous-plastic, 15 iterations, (b) viscous-plastic, 1 iteration, (c) viscousplastic, 5 iterations, (d) elastic-viscous-plastic, (e) cavitating fluid. 
(a)
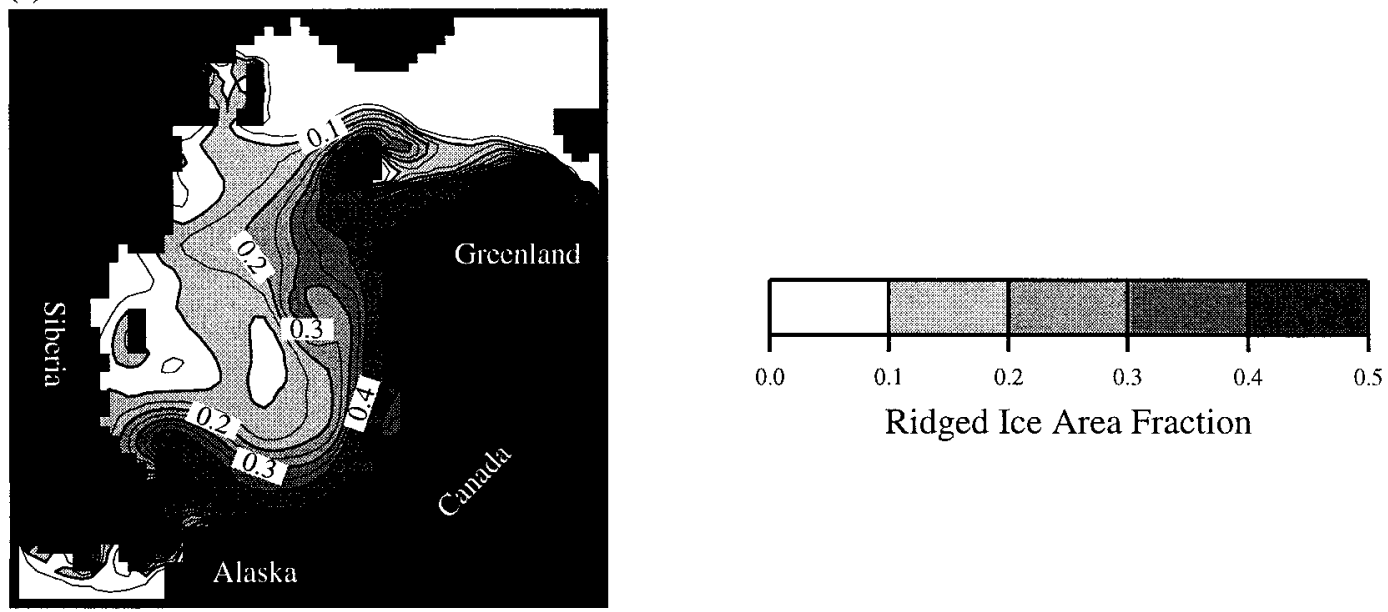

(b)

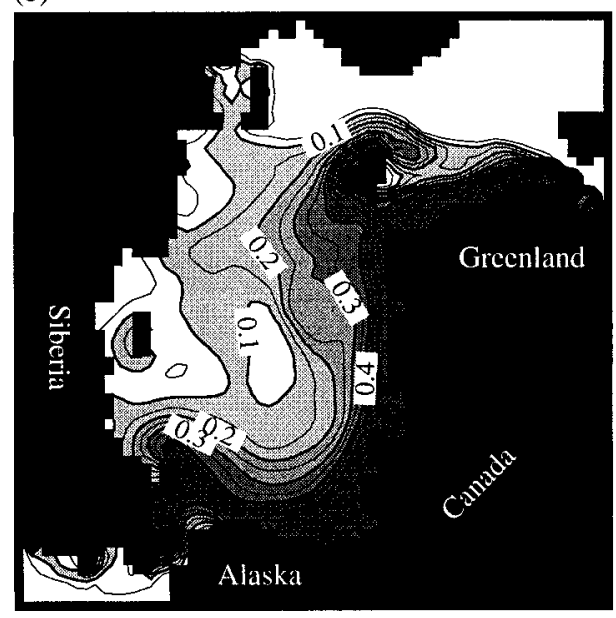

(c)

(d)
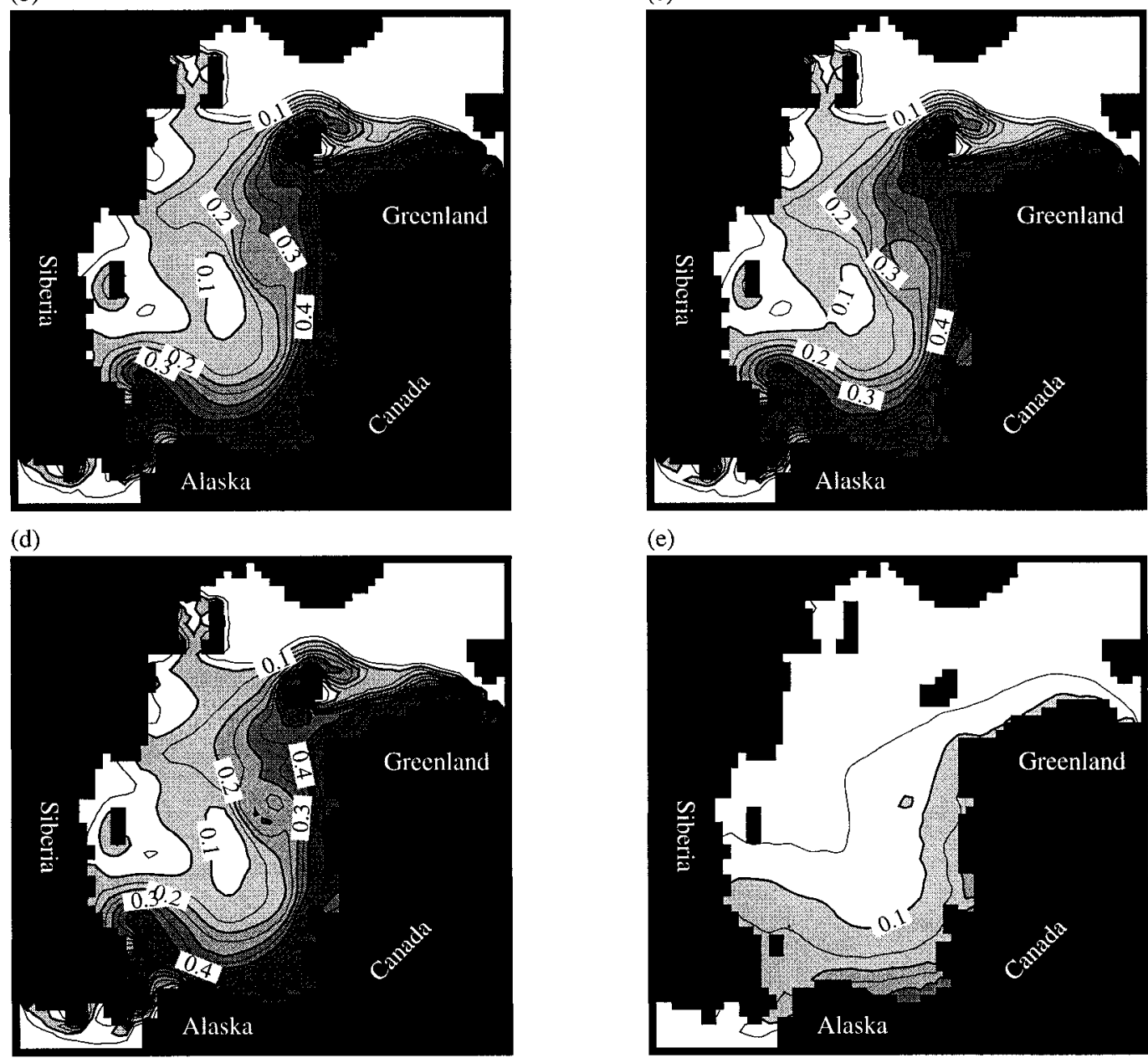

(e)

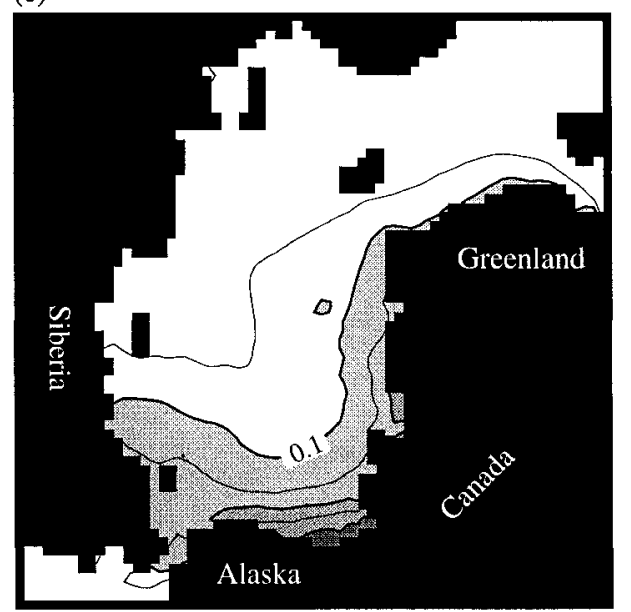

FIG. 5. Baseline March fraction of ridged-ice-covered area for (a) viscous-plastic, 15 iterations, (b) viscous-plastic, 1 iteration, (c) viscous-plastic, 5 iterations, (d) elastic-viscous-plastic, (e) cavitating fluid. 
TABLE 3. CPU time required for 20-yr spinup runs.*

\begin{tabular}{lcc}
\hline \hline \multicolumn{1}{c}{ Rheology } & $\begin{array}{c}\text { 2-category } \\
\text { (h) }\end{array}$ & $\begin{array}{c}\text { 28-category } \\
\text { (h) }\end{array}$ \\
\hline Viscous-plastic, 1 iteration & 3.66 & 27.33 \\
Viscous-plastic, 5 iterations & 12.15 & 37.97 \\
Viscous-plastic, 15 iterations & 25.70 & 53.94 \\
Cavitating fluid & 21.27 & 50.50 \\
Elastic-viscous-plastic & 12.07 & 38.58 \\
\hline
\end{tabular}

* Runs were performed on a Silicon Graphics Power Challenge XL R10000.

rheology for the two-layer case, and is comparable to the viscous-plastic rheology with 15 iterations. This arises because of the more strict convergence criterion used. As mentioned in Zhang and Hibler (1997), their technique can also be used to solve the cavitating fluid equations. Such an implementation would be much faster than any of the viscous-plastic cases (G. Flato 1997, personal communication). However, this more efficient scheme was not used with the cavitating fluid rheology in this study. We note also that improved numerical solution techniques are constantly under development, some of which could substantially improve upon the CPU times presented here. We do not investigate these methods, as our study is focused primarily on comparing the sensitivity of the various ice dynamics formulations.

\section{The effects of a momentum flux perturbation}

In order to investigate the sensitivity of the sea ice models as a function of rheology, each was subjected to a momentum flux perturbation. Cases were run for 30 years, the first 20 under baseline forcing. For the last 10 years, the winds were either increased or decreased by $25 \%$. All other forcing remained the same.

\section{a. Two-category simulations}

The responses of the 2-category simulations to perturbations in momentum flux are shown in Table 1. The most drastic differences are seen in the response of the cavitating fluid model compared to the elliptical yield curve models. While an increase in wind speed brings about an increase in ice thickness in the other models, it decreases the average thickness in the cavitating fluid case. Increasing the wind speed increases open water production. This is seen as a decrease in ice covered area within the Arctic basin in all models. With increased open water (leads), more ice production and hence a greater mean ice thickness should result, as seen in the elliptical yield curve models. However, the increased wind speed also brings about an increase in ice drift and ice transport, as indicated by the kinetic energy per unit mass.

The model responses to a decrease in wind speed are not as straightforward. Annual averages show an increase in mean thickness for all models except the elas- tic-viscous-plastic model. The cavitating fluid responds with an increase in mean thickness for March and September, while the elliptical yield curve rheologies all have a decrease in March mean thickness but an increase in September. The reason for this is that the decreased wind speed means decreased open water production compared to a baseline. This can be seen by increases in ice-covered areas for all the models, and the substantial decrease (greater than 75\%) in March kinetic energy. It is also suggested by Fig. 2, in which more stress states lie within the ellipse, where the viscous flow regularization for small strain rates is in effect. In the winter, there are fewer leads and thus less new ice growth, and the mean thickness drops. However, less of this ice is advected out of the region, leaving more of it at the beginning of the summer melt season. Thus, more ice persists throughout the summer, increasing the mean thickness compared to the baseline. The range of response of the viscous-plastic models with varying iterations on the numerical solver is interesting. It will be more relevant in the next subsection, in which the 28-category ice thickness distribution proves to be important.

\section{b. Ice thickness distribution simulations}

The results for the 28-category model simulations are given in Table 2. The cavitating fluid response seen in the 2-category models is repeated here. Thus, the increased thermodynamic resolution provided by the additional thickness categories does not affect the cavitating fluid rheology's response to perturbations in momentum flux. Meanwhile, the elliptical curve model responses are also analogous to the 2-category simulations. The spatial distribution of thickness anomalies for increased winds compared to the baseline is shown in Fig. 6. As in the 2-category cases, the response is dependent on the shape of the yield curve. It is clear from the figure that the decrease in thickness for the cavitating fluid rheology is nearly basinwide. The elliptical yield curve models, however, show an increase in thickness along the Canadian Archipelago and the north coast of Alaska. When the ice drift (Fig. 4) and ridged ice location (Fig. 5) are taken into account, the regions of increased thickness correspond with regions of convergence and high concentrations of ridged ice. The patterns for the various viscous-plastic results and the elastic-viscous-plastic results are generally similar. Slight differences in the spatial location and magnitude of ice thickness anomalies can be seen throughout the basin, however.

The response of the models to a decrease in wind speed is more interesting. The viscous-plastic results for average ice thickness are strongly dependent on the number of iterations on the numerical solver. With only one iteration, the annual average thickness is $4.21 \mathrm{~m}$, with $98.2 \%$ of the Arctic basin covered with sea ice, and a total kinetic energy of $0.0856 \mathrm{~J} \mathrm{~kg}^{-1}$. Increasing 
(a)

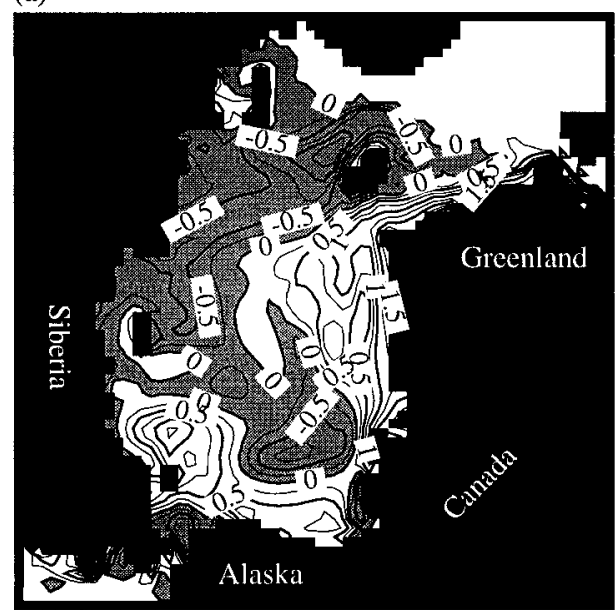

(b)

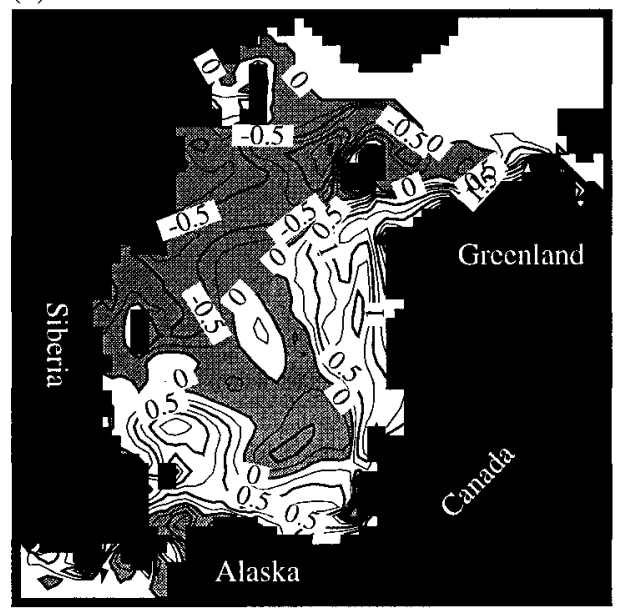

(d)

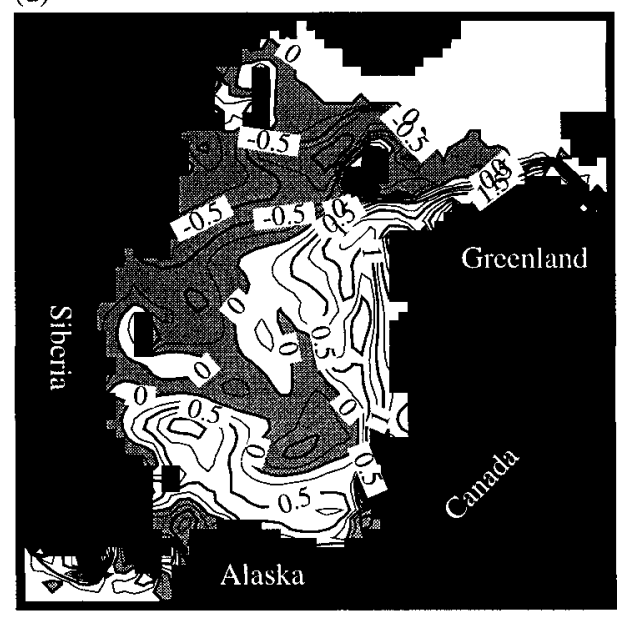

(c)

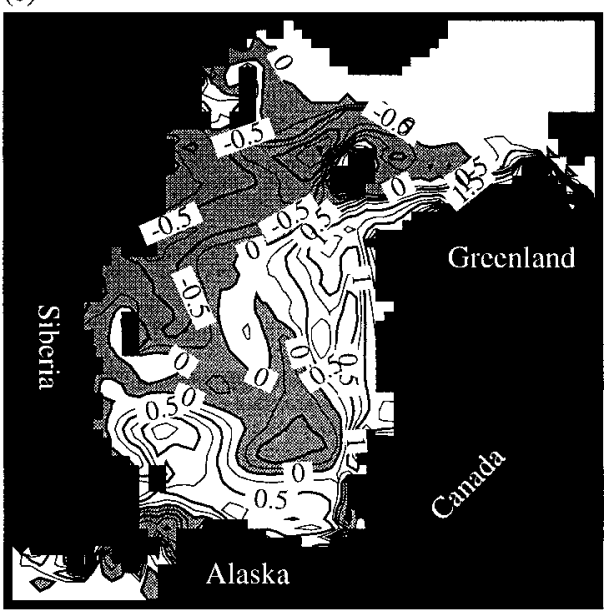

(e)

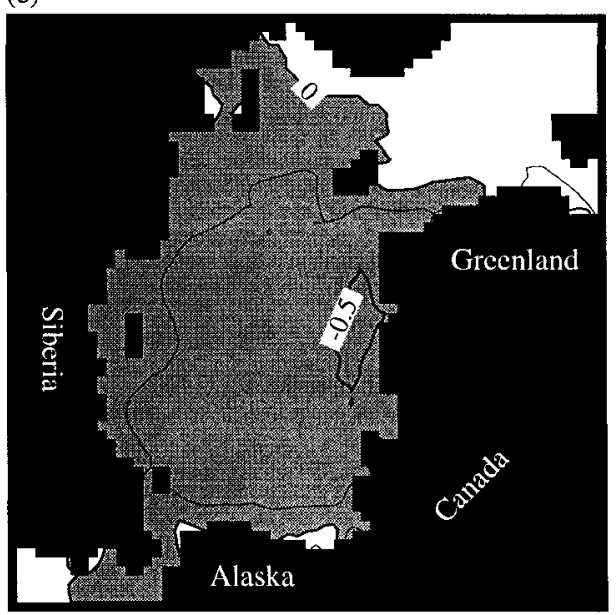

FIG. 6. March thickness anomaly $(\mathrm{m}),+25 \%$ increased winds minus baseline for (a) viscous-plastic, 15 iterations, (b) viscous-plastic, 1 iteration, (c) viscous-plastic, 5 iterations, (d) elastic-viscous-plastic, (e) cavitating fluid. Negative anomalies are gray-shaded. 
TABLE 4. Annual Fram Strait ice export results, 28-category models.

\begin{tabular}{|c|c|c|c|c|c|c|c|c|c|}
\hline \multirow[b]{2}{*}{ Rheology } & \multicolumn{3}{|c|}{ Export $(\mathrm{Sv})$} & \multicolumn{3}{|c|}{ Mean thickness in Strait (m) } & \multicolumn{3}{|c|}{ Mean $\mathrm{u}$ velocity $\left(\mathrm{cm} \mathrm{s}^{-1}\right)$} \\
\hline & Baseline & $\begin{array}{l}+25 \% \\
\text { winds }\end{array}$ & $\begin{array}{l}-25 \% \\
\text { winds }\end{array}$ & Baseline & $\begin{array}{l}+25 \% \\
\text { winds }\end{array}$ & $\begin{array}{l}-25 \% \\
\text { winds }\end{array}$ & Baseline & $\begin{array}{l}+25 \% \\
\text { winds }\end{array}$ & $\begin{array}{l}-25 \% \\
\text { winds }\end{array}$ \\
\hline Viscous-plastic, 1 iterations & 0.103 & 0.154 & 0.043 & 4.45 & 5.34 & 3.10 & 3.92 & 4.95 & 2.52 \\
\hline Viscous-plastic, 5 iterations & 0.096 & 0.142 & 0.053 & 4.46 & 5.27 & 3.48 & 3.65 & 4.60 & 2.66 \\
\hline Viscous-plastic, 15 iterations & 0.098 & 0.142 & 0.056 & 4.50 & 5.27 & 3.55 & 3.68 & 4.64 & 2.70 \\
\hline Elastic-viscous-plastic & 0.107 & 0.149 & 0.067 & 4.24 & 4.88 & 3.48 & 4.21 & 5.14 & 3.23 \\
\hline Cavitating fluid & 0.061 & 0.071 & 0.049 & 2.62 & 2.37 & 2.98 & 3.80 & 4.86 & 2.74 \\
\hline
\end{tabular}

to five iterations, the average thickness drops nearly onehalf meter, to $3.77 \mathrm{~m}, 96.8 \%$ ice-covered area, and $0.1310 \mathrm{~J} \mathrm{~kg}^{-1}$ kinetic energy. A further increase in iterations decreases the thickness to $3.70 \mathrm{~m}, 96.5 \%$ ice covered area, and $0.1378 \mathrm{~J} \mathrm{~kg}^{-1}$. Corresponding behavior is seen in the March and September values, particularly in March. While not as important in the 2-category cases, the number of iterations on the viscousplastic solver becomes crucial when a 28-category ice thickness distribution is used. The elastic-viscous-plastic results compare well with those of the viscous-plastic models for spatial patterns of thickness and area, although the ice motion in the elastic-viscous-plastic cases is somewhat faster. We again note that the stress state plots (not shown) indicate that the elastic-viscousplastic model is not adhering to the elliptical yield curve rule.

\section{c. Fram Strait ice export}

Ice export through Fram Strait is the main connection between the Arctic Basin and the North Atlantic Ocean, and thereby the global ocean. It is important, then, to be able to model the Fram Strait export correctly, in both regular and climate change scenarios. Table 4 summarizes the annual export for the 28-category models. Except for the cavitating fluid model, these results are comparable to the climatological value of $0.097 \mathrm{~Sv}(\mathrm{~Sv}$ $\equiv 10^{6} \mathrm{~m}^{3} \mathrm{~s}^{-1}$ ), derived from Aagard and Carmack (1989). There is considerably more seasonal variability in the cavitating fluid ice export than in the elliptical models. The baseline March values (not shown) for the viscous-plastic models are typically 50\% higher than the annual averages, and about $75 \%$ higher for the elastic-viscous-plastic, while the cavitating fluid March ice export is nearly $150 \%$ higher than its annual average. While all models show an increase in ice export with increased winds, the mean ice thickness in Fram Strait for the cavitating fluid model decreases. Thus, the increase in export there is due to thinner ice that is moving faster. Increases in the elliptical model ice export are due to both increased ice thickness and ice velocity. The viscous-plastic results depend on the number of iterations on the numerical solver, while the elastic-viscousplastic results show generally slightly thinner, fastermoving ice than the viscous-plastic results.

\section{Summary and conclusions}

An intercomparison of three sea ice dynamic models and two ice thickness distributions has been presented. By assessing not only the differences among the baseline results but also the responses of the various models to a momentum flux perturbation, insight is given into their physical behavior. This is useful for appraising the utility of the various models in global climate and climate change studies. It is seen that inclusion of a 28-category ice thickness distribution that explicitly calculates ridging and open water production substantially increases ice thickness throughout the year as well as summer areal coverage. Thus, new ice growth and exchange of heat and moisture between the atmosphere and ocean is affected.

The response of the cavitating fluid model, which lacks a parameterization for shear resistance, differs greatly from those of the viscous-plastic and elasticviscous-plastic formulations, both of which contain a shear strength parameterization. In the 2-category formulation, the responses of the elliptical models are nearly identical, and the number of iterations on the viscousplastic solver has a small, although nonnegligible, effect. The addition of a 28-category ice thickness distribution, however, accentuates the differences between the elliptical rheologies, as well as the importance of the number of iterations on the viscous-plastic numerical solver. Furthermore, it is shown that, in particular, the Fram Strait ice export is sensitive to the type of dynamic model used.

The cavitating fluid model was originally developed for use with smoothed forcing in long-term, crude-resolution climate applications (Flato and Hibler 1992). It lent itself well to implementation in GCMs, necessitated by their requirement for computational speed and efficiency. Currently, several GCMs use the cavitating fluid rheology (e.g., Weatherly et al. 1998). Our results emphasize the importance of including shear strength in the parameterization of sea ice, and given the ongoing improvements in numerical solvers, these more physically realistic rheologies now lend themselves well to GCM use.

While widely accepted among the sea ice modeling community, we would like to emphasize that the elliptical yield curve for sea ice is not necessarily the most correct dynamic parameterization available (e.g., Hibler 
and Schulson 1997). However, it does reproduce well many of the observed physical characteristics of sea ice most important for large-scale modeling, and thus appears adequate for climate model simulations. Here, we have compared a new elliptical numerical method, the elastic-viscous-plastic model, with several formulations of the viscous-plastic model. The elastic-viscousplastic model gives results generally comparable with the viscous-plastic model. In terms of accuracy, it has been argued by many (e.g., Zhang and Hibler 1997; Kreyscher et al. 1997) that a viscous-plastic model, especially with a sufficient number of iterations on the numerical solver to approximate a plastic solution, is the most accurate of the dynamic ice models in wide use, at least when monthly and longer averages are considered. A companion study (Arbetter and Meier 1998 unpublished manuscript) compares modeled ice motions for various implementations of an elliptical yield curve with daily observations derived from satellite and buoy data.

Comparison of stress states of the two models (e.g., Zhang and Hibler 1997; Hunke and Zhang 1999) indicate that the viscous-plastic model obeys the elliptical yield curve constraint much more consistently than the elastic-viscous-plastic model; indeed, the best that the elastic-viscous-plastic model can possibly do is emulate the viscous-plastic model with one iteration (E. Hunke 1997, personal communication). However, Hunke and Zhang (1999) suggest that the elastic-viscous-plastic model is better suited than the viscous-plastic model for implementation on multiprocessor machines. Thus, the choice of which numerical model to use is somewhat dependent on its application. Nevertheless, the results of this study indicate that a elliptical yield curve rheology is well-suited for inclusion in a GCM.

Acknowledgments. We are grateful to G. Flato for his suggestions and help during the development of our model. We also thank J. Zhang and E. Hunke for providing their subroutines. This work was supported by Grants NSF OPP-9614492 and NSF OPP-9423546.

\section{REFERENCES}

Aagard, K., and E. C. Carmack, 1989: The role of sea ice and other fresh water in the Arctic circulation. J. Geophys. Res., 94 (C10), 14 485-14 498.

Broecker, W. S., D. M. Peteet, and D. Rind, 1985: Does the oceanatmosphere system have more than one stable mode of operation? Nature, 315, 21-26.

Fichefet, T., and M. A. Morales Maqueda, 1997: Sensitivity of a global sea ice model to the treatment of ice thermodynamics and dynamics. J. Geophys. Res., 102, 12 609-12 646.

Flato, G. M., and W. D. Hibler, III, 1992: Modeling pack ice as a cavitating fluid. J. Phys. Oceanogr., 22, 626-650.

$\longrightarrow$, and -1995 : Ridging and strength in modeling the thickness distribution of sea ice. J. Geophys. Res., 100, 18 611-18 626.

Gloersen, P., W. J. Campbell, D. J. Cavalieri, J. C. Comiso, C. L. Parkinson, and H. J. Zwally, 1992: Arctic and Antarctic Sea Ice,
1978-1987: Satellite Passive-Microwave Observations and Analysis. NASA SP-511, 290 pp.

Hakkinen, S., 1993: An Arctic source for the Great Salinity Anomaly: A simulation of the Arctic ice-ocean system for 1955-1975. J. Geophys. Res., 98(C9), 16 397-16 410.

Hibler, W. D., III, 1979: A dynamic thermodynamic sea ice model. J. Phys. Oceanogr., 9, 815-846.

— 1980: Modeling a variable thickness sea ice cover. Mon. Wea. Rev., 108, 1943-1973.

—, and K. Bryan, 1987: A diagnostic ice-ocean model. J. Phys. Oceanogr., 17, 987-1015.

- , and E. M. Schulson, 1997: On modeling sea-ice fracture and flow in numerical investigations of climate. Ann. Glaciol., 25, 26-32.

Holland, D. M., L. A. Mysak, and D. K. Manak, 1993: Sensitivity study of a dynamic-thermodynamic sea ice model. J. Geophys. Res., 98, 2561-2586.

Houghton, J. T., L. G. Meira Filho, B. A. Callander, N. Harris, A. Kattenberg, and K. Maskell, Eds., 1996: Climate Change 1995: The Science of Climate Change. Cambridge University Press, $572 \mathrm{pp}$.

Hunke, E. C., and J. K. Dukowicz, 1997: An elastic-viscous-plastic model for sea ice dynamics. J. Phys. Oceanogr., 27, 1849-1867.

- and Y. Zhang, 1999: A comparison of sea ice dynamics models at high resolution. Mon. Wea. Rev., 127, 396-408.

Ip, C. F., W. D. Hibler III, and G. M. Flato, 1991: On the effect of rheology on seasonal sea-ice simulations. Ann. Glaciol., 15, 1725.

Lemke, P., W. D., Hibler, G. Flato, M. Harder, and M. Kreyscher, 1997: On the improvement of sea-ice models for climate simulations: The Sea Ice Model Intercomparison Project. Ann. Glaciol., 25, 183-187.

Kreyscher, M., M. Harder, and P. Lemke, 1997: First results of the Sea-Ice Model Intercomparison Project (SIMIP). Ann. Glaciol., 25, 8-11.

Manabe, S., and R. J. Stouffer, 1980: Sensitivity of a global climate model to an increase of $\mathrm{CO}_{2}$ concentration in the atmosphere. J. Geophys. Res., 85, 5529-5554.

- , and -1988 : Two stable equilibria of a coupled oceanatmosphere model. J. Climate, 1, 841-866.

Mysak, L. A., and S. B. Power, 1992: Sea ice anomalies in the western Arctic and Greenland-Iceland Sea and their relationship to an interdecadal climate cycle. Climatol. Bull., 26(3), 147-176.

_ D. K. Manak, and R. F. Marsden, 1990: Sea-ice anomalies observed in the Greenland and Labrador Seas during 1901-1984 and their relationship to an interdecadal Arctic climate cycle. Climate Dyn., 5, 111-133.

Pollard, D., and S. L. Thompson, 1994: Sea-ice dynamics and $\mathrm{CO}_{2}$ sensitivity in a global climate model. Atmos.-Ocean, 32, 449467.

Rind, D., R. Healy, C. Parkinson, and D. Martinson, 1995: The role of sea ice in $2 \times \mathrm{CO}_{2}$ climate model sensitivity. Part I: The total influence of sea-ice thickness and extent. J. Climate, 8, 449463.

Rothrock, D. A., 1975: The energetics of the plastic deformation of pack ice by ridging. J. Geophys. Res., 80, 4514-4519.

Thorndike, A. S., D. A. Rothrock, G. A. Maykut, and R. Colony, 1975: The thickness distribution of sea ice. J. Geophys. Res., 80, 4501-4513.

Washington, W. M., and G. A. Meehl, 1984: Seasonal cycle experiment on the climate sensitivity due to a doubling of $\mathrm{CO}_{2}$ with an atmospheric general circulation model coupled to a simple mixed layer ocean model. J. Geophys. Res., 89, 9475-9503.

- , and - , 1986: General circulation model $\mathrm{CO}_{2}$ experiments: Snow-sea ice albedo parameterizations and globally averaged surface temperature. Climate Change, 8, 231-241.

Weatherly, J. W., B. P. Briegleb, W. G. Large, and J. A. Maslanik, 1998: Sea ice and polar climate in the NCAR CSM. J. Climate, 11, 1472-1486.

Zhang, J. and W. D. Hibler III, 1997: On an efficient numerical method for modeling sea ice dynamics. J. Geophys. Res., 102, 86918702 . 